\title{
Modeling aerosol transmission of SARS-CoV-2 from human-exhaled particles in a hospital ward
}

\author{
Lip Huat Saw ${ }^{1}$ - Bey Fen Leo ${ }^{2}$ (D) Norefrina Shafinaz Md Nor ${ }^{3}$. Chee Wai Yip ${ }^{3}$ - Nazlina Ibrahim ${ }^{3}$. \\ Haris Hafizal Abd Hamid ${ }^{4}$. Mohd Talib Latif ${ }^{4}$ Chin Yik Lin ${ }^{5} \cdot$ Mohd Shahrul Mohd Nadzir $^{4}$
}

Received: 7 January 2021 / Accepted: 17 May 2021 / Published online: 25 May 2021

(C) The Author(s), under exclusive licence to Springer-Verlag GmbH Germany, part of Springer Nature 2021

\begin{abstract}
The COVID-19 pandemic has plunged the world into uncharted territory, leaving people feeling helpless in the face of an invisible threat of unknown duration that could adversely impact the national economic growths. According to the World Health Organization (WHO), the SARS-CoV-2 spreads primarily through droplets of saliva or discharge from the mouth or nose when an infected person coughs or sneezes. However, the transmission of the SARS-CoV-2 through aerosols remains unclear. In this study, computational fluid dynamic (CFD) is used to complement the investigation of the SARS-CoV-2 transmission through aerosol. The Lagrangian particle tracking method was used to analyze the dispersion of the exhaled particles from a SARS-CoV-2-positive patient under different exhale activities and different flow rates of chilled (cooling) air supply. Air sampling of the SARS-CoV-2 patient ward was conducted for 48-h measurement intervals to collect the indoor air sample for particulate with diameter less than $2.5 \mu \mathrm{m}$. Then, the reverse transcription quantitative real-time polymerase chain reaction (RTqPCR) was conducted to analyze the collected air sample. The simulation demonstrated that the aerosol transmission of the SARS-CoV-2 virus in an enclosed room (such as a hospital ward) is highly possible.
\end{abstract}

Keywords SARS-CoV-2 $\cdot$ Airborne $\cdot$ Virus transmission $\cdot$ PM2.5 $\cdot$ Computational fluid dynamic

Highlights $\cdot$ First simulation study that reports the dispersion of the virus particles can be affected by the cooling air flow in an enclosed hospital ward.

-The flow rates of chilled (cooling) air supply are positively associated with the risk of SARS-CoV-2 infection.

-For strong expiration (e.g., coughing), the velocity of particulate matters is negatively correlated with the flow rate of cooling air flow.

-In an enclosed room, aerosol transmission is one of the possible transmission routes for the SARS-CoV-2.

-Some of the virus particles will be exhausted through the air conditioner inlet.

Responsible Editor: Lotfi Aleya

Bey Fen Leo

beyfenleo@um.edu.my

Mohd Shahrul Mohd Nadzir

shahrulnadzir@ukm.edu.my

1 Lee Kong Chian, Faculty of Engineering and Science, Universiti Tunku Abdul Rahman, 43000 Kajang, Selangor, Malaysia

2 Faculty of Medicine, Universiti Malaya, 50603 Kuala Lumpur, Malaysia

3 Department of Biological Sciences and Biotechnology, Faculty of Science and Technology, Universiti Kebangsaan Malaysia, 43600 Bangi, Selangor, Malaysia

4 Department of Earth Sciences and Environment, Faculty of Science and Technology, Universiti Kebangsaan Malaysia, 43600 Bangi, Selangor, Malaysia

5 Department of Geology, Faculty of Science, Universiti Malaya, 50603 Kuala Lumpur, Malaysia 


\section{Introduction}

The coronavirus disease 2019 (COVID-19) caused by SARSCoV-2 was first reported in China in December 2019 and led to life-threatening pneumonia. The coronavirus outbreak was declared a pandemic by the World Health Organization (WHO) on March 11, 2020. To date, the WHO has recorded more than 159 million positive cases and 3.3 million deaths (Dong et al. 2020). Malaysia alone has confirmed more than 453,000 cases and 1,761 deaths by the Ministry of Health (Dong et al. 2020). According to WHO, the SARS-CoV-2 is primarily transmitted between people through respiratory droplets and contact routes with respiratory droplets of particle size $>5$ to $10 \mu \mathrm{m}$ in diameter (Chan et al. 2020; Liu et al. 2020a; WHO 2007).

Droplet transmission occurs when a person is in close contact (within $1 \mathrm{~m}$ ) with a SARS-CoV-2 patient experiencing respiratory symptoms such as coughing, shouting, or sneezing. Mucosal membranes of the mouth and nose or conjunctiva exposed to potentially infective respiratory droplets from a symptomatic patient are the possible transmission of the SARS-CoV-2 via fomites which is also evident (Burke et al. 2020; Liu et al. 2020a; Ong et al. 2020). Therefore, the transmission of the SARS-CoV-2 virus can occur via direct contact with infected people and indirect contact with surfaces in the environment (fomites) (Guo et al. 2020). In addition, the WHO also emphasizes a possible airborne transmission of the virus via aerosol generation (particle diameter $<5 \mu \mathrm{m}$ ) (Wang and Du 2020). Effective strategies such as surface cleaning, contact and isolation precautions, and vaccine regimens have been recommended and implemented by local authorities globally to break the chain of infection.

It is reported that larger droplets rapidly fall to the ground surfaces within 1-2 $\mathrm{m}$ from the source resulting in the measures applied for social distancing (Jones et al. 2020). By increasing the ventilation rate and pressure differentials, the rate of short-range transmission does not reduce significantly. Depending on the environmental factors, these large-diameter droplets may shrink (due to evaporation) before they settle or collide with each other to form smaller particles $(<10 \mu \mathrm{m})$ namely aerosols. These evaporated droplet residuals or aerosols can remain airborne for several hours, traveling over a long distance before infecting secondary hosts (Bourouiba 2020). A study has shown that aerosols are primarily affected by the air flow patterns in the environment (Jayaweera et al. 2020). Although air ventilation does not significantly change the settling course of larger droplets, it promotes the transmission of SARS-CoV-2 via fine aerosols. Specifically, directional air flow can create laminar or turbulent flow patterns and transport the infectious aerosols around. Several airbornerelated outbreaks of this viral disease have been documented. Virus transmission was reported in an air conditioned restaurant in Guangzhou, China, which involved three family clusters. The study showed that the air flow direction was consistent with droplet transmission ( $\mathrm{Lu}$ et al. 2020). Moreover, a study in inner Mongolia of China showed that a person was confirmed SARS-CoV-2 positive when he walked pass a house of a COVID-19 patient with the door open (Wang and Du 2020). Furthermore, Ong et al. (2020) also detected positive SARS-CoV-2 in the air exhaust outlets of the SARS-CoV-2 outbreak center in Singapore, suggesting the possibility of airborne transmission. However, there has been no clear evidence of how the exhaust outlet was contaminated. Therefore, the understanding of the building's heating, ventilation, and air conditioning (HVAC) operational practices to reduce the spread of the SARS-CoV-2 is of urgent need (Dietz et al. 2020; Liu et al. 2020b). Although there is no concrete evidence on the minimum infectious viral load for the SARS-CoV-2 to cause the infection, several researchers estimated that a few hundreds of virus particles would be enough to infect a person (Beggs 2020; Science Media Centre 2020).

Yang et al. (2017) used computational fluid dynamic (CFD) simulation to predict the dispersion of cough-jet in an airline cabin. The simulation only considered one row of passenger's seat and it was reported that the cough-jet affects the air flow field in front of the coughing passenger. Redrow et al. (2011) used a numerical model to predict the dispersion of the coughing droplet using particles with three different sizes - 1 $\mu \mathrm{m}, 10 \mu \mathrm{m}$, and $100 \mu \mathrm{m}$. The study found that the evaporation of the droplet is largely affected by the relative humidity of the environment. Furthermore, Jayaweera et al. (2020) deduced the dispersion of the SARS-CoV-2 inside a vehicle (as well as the effect with a face mask or without a face mask) based on the simulation results reported by Khatoon and Kim (2020). In a confined environment, the dispersion of the droplets and aerosols showed complex behavior. Since multiple studies have demonstrated the transmission of SARS-CoV-2 is directly linked to the dispersion of droplets and aerosols generated from a COVID-19-positive patient, hence, there is a necessity to further investigate the transport mechanism of the infectious droplets and aerosols to control the spreading of the virus. In this case, computational fluid dynamics was adopted to predict the transport phenomenon of droplet and aerosol exhaled from a COVID-19 patient.

Given the aforementioned phenomena, it is clear that understanding the transmission of the SARS-CoV-2 within indoor space is crucial, especially in healthcare premises. In China alone, as many as 1716 healthcare workers have been infected due to poor understanding of the spreading route in hospital environments (Tang et al. 2020), whereas in the USA, approximately 9000 healthcare workers were being confirmed positive for a similar reason. As a result, minimizing nosocomial transmission and ventilation may significantly reduce disease transmission rates. Healthcare facilities including hospitals are potential hotspots for the spread of COVID-19 via 
human-to-human transmissions in a confined environment. Thus, atmospheric forensic studies are important to better understand the transmission of the SARS-CoV-2 facilitated by PM produced by COVID-19 patients in an indoor environment.

Herein, a computational fluid dynamic technique with Lagrangian particle tracking is employed to complement our previous studies on detecting the SARS-CoV-2 virus in the air sampler of the enclosed single occupant ward in the hospital in Kuala Lumpur (Md et al., 2020). Three different velocities representing weak, medium, and strong human expiration with three different flow rates of cooling air were simulated. The dispersion of the SARS-CoV-2 virus particle under the influence of various patient exhalation activities and different cooling air flow rates by the ceiling cassette air conditioner were investigated. A low-volume air sampler was used to collect the air sample in the single-bed ward within 48-h intervals. Reverse transcription quantitative real-time polymerase chain reaction (RT-qPCR) test was conducted to confirm the detection of the SARS-CoV-2 from the air sampling. Lastly, a new air conditioner design with supply diffusers, room return, and aerosol arrestor was proposed to reduce the dispersion of the exhaled particles. These findings may provide key information on the role of the droplets and aerosols in SARS-CoV-2 transmission. Furthermore, this study also offers better knowledge when designing an ideal ward condition to protect healthcare workers from exposure to viruses while managing patients.

\section{Air sampling, monitoring, and numerical modeling of the single occupant ward}

\section{Air sampling and virus analysis}

This current study was an extension from the study previously conducted by Md et al. (2020). Briefly, air sampling of the SARS-CoV-2 patient ward was conducted for 48-h measurement intervals at a hospital in Kuala Lumpur, Malaysia (31 March to 4 April 2020) to collect the indoor air sample. Two different types of equipment were installed in the ward to monitor and collect the air sample as shown in Fig. 1. The equipment is a low-volume sampler (MiniVol, AirMetrics, USA) and in-house air quality sensor AiRBOXSense (UKM Tech Sdn Bhd, Malaysia). AiRBOXSense was used to measure and monitor the $\mathrm{PM}_{2.5}$ inside the ward. Quartz microfiber filters (Whatman) with pore size of 0.6 to $0.8 \mu \mathrm{m}$ were used for particle retention. The filter papers in the low-volume sampler situated about $1.2-1.5 \mathrm{~m}$ from the patient's bed were collected in the single-bed ward within 48-h intervals, then stored in a sealed container and kept in the freezer at -80 ${ }^{\circ} \mathrm{C}$. This was followed by virus genome extraction and RTqPCR according to the guidelines suggested by the Centres for
1 AiRBOXSense

2 Low Volume Sampler

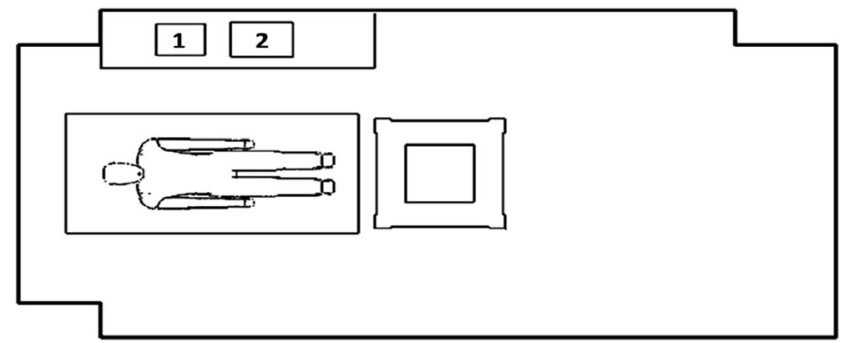

Fig. 1 Floor plan/layout of a single-bed ward, and the position of air sampler (LVS) and monitoring sensors (AiRBOXSense)

Disease Control and Prevention (CDC) to validate the presence of SARS-CoV-2 in the air of the room exhaled from the patient. The air flow simulation was used to complement the air sampling work and gain insight into the dispersion mechanism of the SARS-CoV-2 virus-laden aerosol in the room and potential sites where particle deposition is plausible under the influence of air flow.

\section{Single-bed ward model}

The CAD model of the single-bed ward was constructed using commercial CAD software-Solidworks 2017. Figure 1 shows the improvised ward layout version adopted from $\mathrm{Md}$ et al. (2020) where the dimension of the ward is $5960 \mathrm{~mm}$ (length) $\times 2830 \mathrm{~mm}$ (width) $\times 2900 \mathrm{~mm}$ (height) and the dimension of the bed is $2140 \mathrm{~mm}$ (length) $\times 1040 \mathrm{~mm}$ (width) $\times 760 \mathrm{~mm}$ (height). The ceiling cassette air conditioner installed in the room supplies up to three different flow rates which are 13.5, 17.5, and 21.0 CMM. The ceiling cassette air conditioner has four outlets opening at 40 degrees to the horizontal with each outlet opening area of $0.045958 \mathrm{~m}^{2}$ to supply cooling air flow at $24{ }^{\circ} \mathrm{C}$. In the study, the bed was placed at the center of the room adjacent to the wall. The human subject was modeled in the analysis to better understand the influence of air flow on human expiration. The SARS-CoV-2positive patient lying on the middle of the bed assumed particles were exhaled from the mouth through various human exhalation activities. The ceiling cassette air conditioner was located at the center of the room near the leg of the patient.

\section{Numerical procedures}

Numerical modeling of the air flow field in the ward was conducted using commercial computational fluid dynamics (CFD) simulation software ANSYS-CFX. CFD analysis was used to accomplish the experimental work and to gain insight into the air flow field and transport of the virus particle that was difficult to visualize. Several assumptions that used to model the transport phenomena of the virus particles from the expiration of the patient are listed below: 
1. Unsteady exhalation particle tracking.

2. The air flow in the ward is incompressible.

3. No thermal energy source in the fluid.

4. No evaporation of the droplet or aerosol expelled from the patient mouth.

\section{Governing equation}

In the numerical simulation, the air was treated as continuous fluid and the particle exhaled from the patient was treated as particle transport fluid. The dispersion of the exhaled particles was solved using the Lagrangian particle tracking model. The exhaled particles are described using the equation below by considering the effects of Stokes' drag, gravity, and variation of pressure (Zhu et al. 2006).

$m_{p} \frac{d u}{d t}=F_{D}+F_{P}+F_{G}$

The drag force, pressure force, and pressure force are described in the equation below:

$F_{G}=V_{d}\left(\rho_{p}-\rho_{a}\right) g$

where $V_{d}$ represents the volume of the droplet, $\mathrm{m}^{3} ; \rho_{\mathrm{p}}$ represents the particle density, $\mathrm{kg} / \mathrm{m}^{3} ; \rho_{\mathrm{a}}$ represents the air density, $\mathrm{kg} / \mathrm{m}^{3} ; \mathrm{g}$ represents the gravity acceleration, $\mathrm{m} / \mathrm{s}^{2}$.

$F_{P}=-V_{d} \nabla p$

$F_{p}$ represents the pressure force due to far-field pressure gradients.

$F_{D}=\frac{1}{2} C_{D} A_{p} \rho_{a}\left|u-u_{p}\right|\left(u-u_{p}\right)$

where $\mathrm{C}_{\mathrm{D}}$ represents the drag coefficient; $A_{p}$ represents the project area of the particle $\left(=\pi \mathrm{d}_{\mathrm{p}}{ }^{2} / 4\right), \mathrm{m}^{2} ; d_{p}$ represents the particle diameter, $\mathrm{m} ; u_{p}$ represents the relative velocity between the particle and the fluid, $\mathrm{m} / \mathrm{s}$.

For the particle in the air with particle's density larger than the density of air $\left(\rho_{\mathrm{p}}>>\rho_{\mathrm{S}}\right)$, following approximations for coefficients of drag, $C_{D}$ was used (Flagan and John 1988).

$C_{D}= \begin{cases}\frac{24}{R e}, & \operatorname{Re}<0.1 \text { (Stokes }{ }^{\prime} \text { law) } \\ \frac{24}{\operatorname{Re}}\left[1+\frac{3}{16} \operatorname{Re}+\frac{9}{160} \operatorname{Re}^{2} \ln (2 \mathrm{Re})\right], & 0.1<\operatorname{Re}<2 \\ \frac{24}{\operatorname{Re}}\left[1+0.15 \operatorname{Re}^{0.687}\right], & 2<\operatorname{Re}<500 \\ 0.44, & 500<\operatorname{Re}<2 \times 10^{5}\end{cases}$

Reynolds number of the droplet is given by (McPherson 1993).
$\operatorname{Re}=\frac{\rho_{a}\left(u-u_{p}\right) d_{p}}{\mu_{a}}$

where $\mu_{\mathrm{a}}$ represents dynamic viscosity of the air, $\mathrm{Ns} / \mathrm{m}^{2}$.

The velocity $(u)$ of the air flow was given by the summation of the random perturbation to the local average velocity (Zhu et al. 2006):

$u=\widetilde{u}+u^{\prime}$

The variable velocity component is derived from the Gaussian probability density function as equation below (Zhu et al. 2006):

$G\left(u^{\prime}\right)=\frac{1}{\sqrt{2 \pi \sigma}} \exp \left(-\frac{u^{\prime 2}}{2 \sigma^{2}}\right)$

The standard deviation $(\sigma)$ is defined by the following equation (Zhu et al. 2006):

$\sigma=\sqrt{2 k / 3}$

The terminal velocity of the particle is defined by the equation below (McPherson 1993):

$v_{t}=\frac{d_{p}^{2} g\left(\rho_{p-} \rho_{a}\right) C_{c}}{18 \mu_{a}}$

where $\mathrm{C}_{\mathrm{c}}$ represents the slip correction factor and can be approximated by using the equation below (Pandis 2000):

$C_{c}=1+\frac{2 \lambda}{d_{p}}\left[1.257+0.4 \exp \left(-\frac{1.1 d_{p}}{2 \lambda}\right)\right]$

where $\lambda$ represents the mean free path of the air, $m$.

The relaxation time of the particle is defined by the equation below (McPherson 1993).

$\tau=\frac{v_{t}}{g}$

Continuity of mass, Navier-Stokes equations of momentum, and energy equations were used to model the air flow field in the single-bed ward (Eq. (12) to Eq. (16)).

The air (or carrier phase) of the exhalation particle is described as a continuum in an inertia reference frame. The continuity equation is given below (Saw et al. 2018):

$\frac{\partial \rho}{\partial t}+\nabla \cdot(\rho \boldsymbol{u})=0$

Momentum equation in $\mathrm{X}, \mathrm{Y}$, and $\mathrm{Z}$ direction is described in Eq. (13) to Eq. (15) (Saw et al. 2018; Versteeg and Malalasekera 1995). 
X-momentum

$\frac{\partial(\rho u)}{\partial t}+\nabla \cdot(\rho u \boldsymbol{u})=-\frac{\partial P}{\partial x}+\nabla \cdot(\mu \nabla u)+S_{M x}$

Y-momentum

$\frac{\partial(\rho v)}{\partial t}+\nabla \cdot(\rho v \boldsymbol{u})=-\frac{\partial P}{\partial y}+\nabla \cdot(\mu \nabla v)+S_{M y}$

Z-momentum

$\frac{\partial(\rho w)}{\partial t}+\nabla \cdot(\rho w \boldsymbol{u})=-\frac{\partial P}{\partial z}+\nabla \cdot(\mu \nabla w)+S_{M z}$

The energy equation for the air is described in the equation below.

$\frac{\partial(\rho i)}{\partial t}+\nabla \cdot(\rho i \boldsymbol{u})=-p \nabla \cdot u+\nabla \cdot(k \nabla T)+\Phi+S_{i}$

The unknown thermodynamic variables $(\rho, \mathrm{P}, i$, and $T)$ in the above equations were obtained through thermodynamic equilibrium. Equations of the state were used to relate the variables to the two-state variables (Versteeg and Malalasekera 1995).

$P=\rho R T$

$h_{f}=\int_{T_{r e f}}^{T_{f}} C_{p f} d T_{f}$

The standard $\mathrm{k}-\varepsilon$ turbulence model in the equation below is used to simulate the flow conditions in the hospital ward (Launder 1972; Santana et al. 2020; Saw et al. 2018; Versteeg and Malalasekera 1995).

$\rho_{f} \frac{\partial k}{\partial \tau}+\rho_{f} \nabla(\boldsymbol{u} k)=\nabla\left(\frac{\mu_{t}}{\sigma_{k}} \nabla k\right)+G_{k}-\rho_{f} \varepsilon+S_{k}$
$\rho_{f} \frac{\partial \varepsilon}{\partial \tau}+\rho_{f} \nabla(\boldsymbol{u} \varepsilon)=\nabla\left(\frac{\mu_{t}}{\sigma_{\varepsilon}} \nabla \varepsilon\right)+C_{1 \varepsilon} \frac{\varepsilon}{k} G_{k}-C_{2 \varepsilon} \rho_{f} \frac{\varepsilon^{2}}{k}+S_{\varepsilon}$

where $k$ is the turbulence kinetic energy, $\varepsilon$ is the turbulence dissipation rate, $S_{k}$ is the source term for $k, S_{\varepsilon}$ is the source term for $\varepsilon, \sigma_{k}$ is the turbulent Prandtl number for $\mathrm{k}$, and $\sigma_{\varepsilon}$ is the turbulent Prandtl number for $\varepsilon$.

$\mu_{\mathrm{t}}$ and $\mathrm{G}_{\mathrm{k}}$ are represented by Eq. (20) and Eq. (21).

$\mu_{t}=\rho_{f} C_{\mu} \frac{k^{2}}{\varepsilon}$

$G_{k}=\mu_{t}\left[\nabla \boldsymbol{u}+(\nabla \boldsymbol{u})^{T}\right] / \nabla \boldsymbol{u}$

\section{Numerical setup and boundary conditions}

Three-dimensional steady-state simulations with Lagrangian particle tracking were conducted to investigate the dispersion of the particles exhaled by the SARS-CoV-2 patient under different exhalation activities. Few studies showed that particles detected during sneezing and coughing are larger than $1 \mu \mathrm{m}$ (Fabian et al. 2011; Tang et al. 2013; Yang et al. 2007), while almost $98 \%$ of the particles detected during tidal breathing are less than $1 \mu \mathrm{m}$ (Edwards et al. 2004). In this study, the particle sizes were selected to give more resolution for fine particles to validate the previous experimental results and experimental study from previous research (Aliabadi et al. 2010, Edwards et al. 2004, Fabian et al. 2011, Kwon et al. 2012, Md et al. 2020, Tang et al. 2013, Xie et al. 2009, Yang et al. 2007). In total, 3000 particles were being used in this study. The particles were grouped into ten different sizes ranging from large particles $(10 \mu \mathrm{m})$ to the smallest particles (70 $\mathrm{nm}$ equal to the size of a virus particle). The distribution of the particle size used in the simulation is $0.07 \mu \mathrm{m}, 0.1 \mu \mathrm{m}$, $0.3 \mu \mathrm{m}, 0.5 \mu \mathrm{m}, 0.8 \mu \mathrm{m}, 1.0 \mu \mathrm{m}, 2.0 \mu \mathrm{m}, 5.0 \mu \mathrm{m}, 8.0 \mu \mathrm{m}$, and $10 \mu \mathrm{m}$. Besides, the transport phenomenon of the droplet and aerosol particles exhaled by the patient under the influence of different cooling air flow rates was also investigated. Three different mass flow rates and velocities (weak, medium, and strong expiration of the SARS-CoV-2-positive patient) were assigned to the mouth (Kwon et al. 2012; Xie et al. 2009). In modeling of the weak expiration (e.g., breathing), the velocity of $1.3 \mathrm{~m} / \mathrm{s}$ and particle mass flow rate of $0.01 \mathrm{gs}^{-1}$ were assigned to the mouth of the patient. On the other hand, modeling of medium expiration (e.g., talking), the maximum velocity of $4.5 \mathrm{~ms}^{-1}$, and particle mass flow rate of $0.05 \mathrm{gs}^{-1}$ were assigned to the mouth of the patient. Lastly, in the modeling of strong expiration such as coughing, the maximum velocity of $15.3 \mathrm{~ms}^{-1}$ and particle mass flow rate of $0.1 \mathrm{gs}^{-1}$ were assigned (Kwon et al. 2012). A total of nine cases were analyzed from an air conditioned single-bed ward.

ANSYS ICEM CFD 19.0 with a hybrid meshing technique was used to discretize the executive ward for the CFD analysis. The $\mathrm{Y}+$ value for this computation domain is calculated using Eq. (23) and ensured the $\mathrm{Y}+$ value is around 11 (Ahmed et al. 2021; Ansys 2009).

$Y^{+}=\frac{y \mu_{T}}{v}$

$\mathrm{y}$ is the absolute distance from the wall of the ward, $\mathrm{m} ; \mu_{\mathrm{T}}$ is the friction velocity, $\mathrm{ms}^{-1} ; \nu$ is the kinematic viscosity, $\mathrm{m}^{2} \mathrm{~s}^{-1}$.

There are five inflation layers being generated in the current computation domain and the first node is placed to capture the buffer layer of the turbulence. In addition, near-wall treatment is maintained with scalable wall function to facilitate better accuracy in turbulence calculation (Ahmed et al. 2021, Ansys 2009). Different size of the computational domain is generated to ensure that the computed results are independent of the grid. The gridindependent test result will be discussed in the following section. The meshed model of the single-bed ward is illustrated in Fig. 2. 
Inflation layers were created to capture the information at the boundary layer region.

The cooling air supply by the ceiling cassette air conditioner was using air properties at $25^{\circ} \mathrm{C}$ and the water properties were assumed as exhaled particle expelled from the patient's mouth. Mass flow boundary conditions with a medium turbulence intensity of $5 \%$ and temperature of $24^{\circ} \mathrm{C}$ were assigned to the four outlets of the ceiling cassette air conditioner. Moreover, the inlet of the air conditioner was assigned as the opening and pressure boundary condition, whereas nonslip wall and adiabatic wall boundary conditions were assigned for the bed and wall of the ward. The computational domain of the ward was set at 1-atm pressure.

The boundary conditions of the ward used in the CFD simulation is illustrated in Fig. 3 and the boundary condition details are summarized in Table 1. A high-resolution advection scheme and first-order turbulence numerics were used for all CFD simulation cases. Tight convergence criteria were applied for continuity, momentum, and energy equations with root mean square residual fall below $1 \times 10^{-6}$. As a result, nine simulation cases were conducted in this study as shown in Table 2.

\section{Mesh independent test}

The density of the mesh significantly affects the accuracy of the result. Hence, a mesh independent test is needed to test if the simulation results are independent of mesh sizing. In this study, the discrepancy of the velocity was kept less than $1 \%$. The results of the mesh independent test for the ward are illustrated in Fig. 4. The mesh independent test was conducted with an air conditioner flow rate of 13.5 cubic meter per minute (CMM). As shown in Fig. 3, four different sets of mesh sizing are generated with M1 (coarse) with 750617 elements, M2 (medium) with 1153959 elements, M3 (fine) with 2546694 elements, and M4 (finest) with 10418874 elements

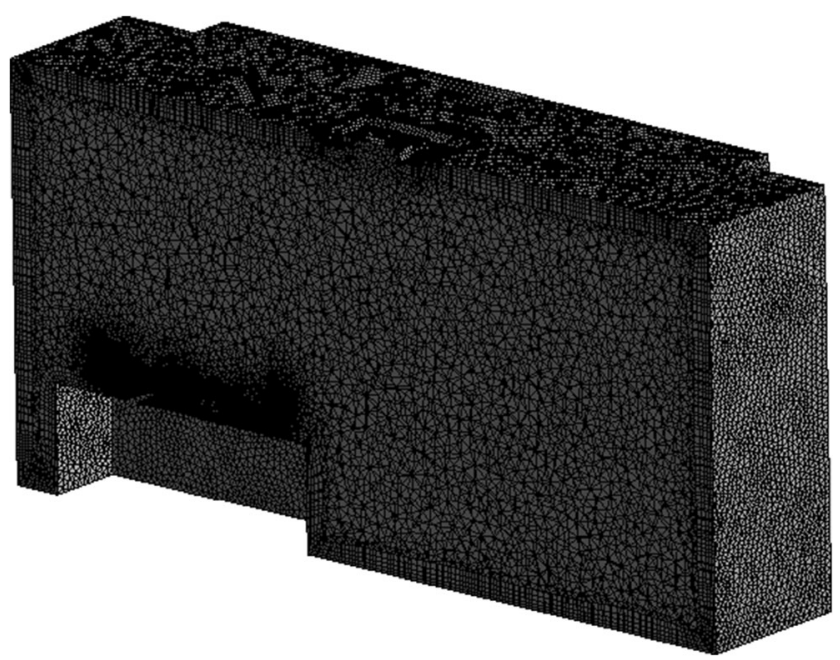

Fig. 2 Meshed model of the single-bed ward

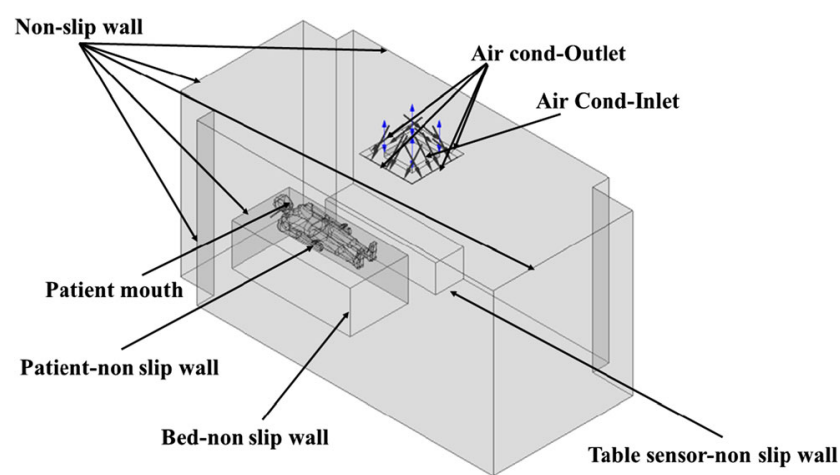

Fig. 3 Boundary conditions of the single-bed ward

to assess the impact of the mesh size on the velocity at point $(0.4,2.5,0.479)$ which is near to the patient mouth. The mesh independent test by monitoring the point location was also adopted in the Li et al. (2020b) study.

The relative deviation in the computed velocity for $\mathrm{M} 2$ to $\mathrm{M} 1, \mathrm{M} 3$ to $\mathrm{M} 2$, and $\mathrm{M} 4$ to $\mathrm{M} 3$ is $33.69 \%, 0.59 \%$, and $0.1 \%$, respectively. This shows that mesh M3 with 2546694 elements is sufficient to model the air flow field in the ward and dispersion of the exhalation particle from the patient in the room. CFD modeling was performed on the workstation equipped with Intel i7-6800K, $3.40 \mathrm{GHz} \mathrm{CPU}$, and $112 \mathrm{~GB}$ RAM. The total computational time was approximately $35 \mathrm{~h}$.

\section{Proposed new air conditioner configuration}

The air flow patterns, thermal comfortability, and distribution of the aerosol particles in the patient room depend on numerous factors such as the presence of air conditioner, the flow rate of fresh air diffusers, the location of fresh air diffusers, and room return. Past literature showed that the design of the ventilation system and air flow pattern are important criteria that affect the flow path of the particles (Licina et al. 2015; Pantelic and Tham 2013). In this study, a new air conditioner design with ceiling supply diffusers, room return, and aerosol arrestor as shown in Fig. 5 was proposed for the patient room. Since the size of the single-bed ward was identical to the study conducted by Khankari (2017), a similar air change rate was adopted for the current study. The fresh air is supplied through three air diffusers and the size of the air diffuser is about $1.2 \mathrm{~m}$ length $\times 0.025 \mathrm{~m}$ width at an angle of $15^{\circ}$ to the ceiling (Khankari 2017). Each of the two air diffusers at the side of the patient supplies $1.98 \mathrm{CMM}$ of fresh air at $24{ }^{\circ} \mathrm{C}$. On the other hand, the linear air diffuser facing the patient supplies $2.46 \mathrm{CMM}$ of fresh air at $24{ }^{\circ} \mathrm{C}$. Hence, the total fresh air supplied to the room is about $6.42 \mathrm{CMM}$. The return diffuser is located at the center of the room and the dimension is about $0.5 \mathrm{~m} \times 0.5 \mathrm{~m}$. An aerosol arrestor was proposed to capture the exhaled particles from the patient and reduce the dispersion of the particles (transmission risk) to the healthcare worker. The opening size of the aerosol arrestor is approximately $1.05 \mathrm{~m} \times$ 
Table 1 Boundary conditions details of the single-bed ward with non-intubation COVID-19 patient in ANSYS CFX

\begin{tabular}{|c|c|c|}
\hline \multirow{2}{*}{$\begin{array}{l}\text { Boundary name } \\
\text { Fluid domain }\end{array}$} & \multicolumn{2}{|l|}{ Boundary details } \\
\hline & Patient body and bed & Non-slip wall \\
\hline & Patient body and bed heat transfer & Adiabatic \\
\hline & Ward wall & Non-slip wall \\
\hline & Ward heat transfer & Adiabatic \\
\hline & Heat transfer & Fluid dependent \\
\hline \multirow[t]{2}{*}{ Fluid specific models } & Air heat transfer model & Thermal energy \\
\hline & Saliva heat transfer model & Particle temperature \\
\hline \multirow[t]{5}{*}{ Air conditioning outlet } & Temperature & $24^{\circ} \mathrm{C}$ \\
\hline & Turbulence intensity & $5 \%$ \\
\hline & Flow rate & 13.5 CMM \\
\hline & & $17.5 \mathrm{CMM}$ \\
\hline & & $21.0 \mathrm{CMM}$ \\
\hline Air conditioning inlet & Opening pressure & $0 \mathrm{~Pa}$ \\
\hline \multirow[t]{7}{*}{ Patient mouth } & Saliva mass flow rate & $0.01 \mathrm{gs}^{-1}$ \\
\hline & & $0.05 \mathrm{gs}^{-1}$ \\
\hline & & $0.1 \mathrm{gs}^{-1}$ \\
\hline & Average velocity & $1.3 \mathrm{~ms}^{-1}$ \\
\hline & & $4.5 \mathrm{~ms}^{-1}$ \\
\hline & & $15.3 \mathrm{~ms}^{-1}$ \\
\hline & Temperature & $37.8^{\circ} \mathrm{C}$ \\
\hline
\end{tabular}

$0.5 \mathrm{~m}$ and the suction rate is $\sim 5 \mathrm{CMM}$ (placed near the patient's mouth). Note that the suction flow rate is the minimum flow rate required to cater for weak to strong exhalation.

\section{Results and discussion}

\section{Respiratory droplet transmission as a function of particle size}

Numerical simulation of the patient's exhaled behavior involving two-phase flow is a complex transport phenomenon.
Fine particles of various size were detected during different exhalation activities from the patients. The terminal velocity and relaxation time of the particles used in the simulation were calculated using Eq. (9) and Eq. (11) as tabulated in Table 3. Terminal velocity of the particles is defined as the free-falling speed of a particle under the influence of gravity. However, the falling of the particle further depends on other environmental factors such as forced convection, heat source, and humidity. The modeling result showed that fine particles as small as $70 \mathrm{~nm}$ can suspend in the air for a longer duration (up to $4137.4 \mathrm{~h}$ ) than particles with a larger size without the influence of air flow.
Table 2 Simulation cases with different boundary conditions

\begin{tabular}{llll}
\hline Case & Cooling air flow rate, CMM* & Saliva velocity, $\mathrm{m} / \mathrm{s}$ & Saliva mass flow rate, $\mathrm{g} / \mathrm{s}$ \\
\hline Case 1 & 13.5 & 1.3 & 0.01 \\
Case 2 & 13.5 & 4.5 & 0.05 \\
Case 3 & 13.5 & 15.3 & 0.10 \\
Case 4 & 17.5 & 1.3 & 0.01 \\
Case 5 & 17.5 & 4.5 & 0.05 \\
Case 6 & 17.5 & 15.3 & 0.10 \\
Case 7 & 21.0 & 1.3 & 0.01 \\
Case 8 & 21.0 & 4.5 & 0.05 \\
Case 9 & 21.0 & 15.3 & 0.10 \\
\hline
\end{tabular}

*CMM cubic meter per minute 
According to the literature, the size of SARS-CoV-2 ranges from 65 to $125 \mathrm{~nm}$ (Kim et al. 2020; Shereen et al. 2020). The virus particles that inhabit the droplet or plumes of aerosols generated by human exhalation (e.g., sneezing, coughing, talking, and tidal breathing) can disperse in the air for an extended amount of time and distance (Milton et al. 2013). Bourouiba (2020) found that particles can travel more than 6 $\mathrm{m}$ and further than the recommendation $(6 \mathrm{ft}$ or $2 \mathrm{~m}$ ) from the Centers for Disease Control and Prevention (CDC). Hence, the healthcare workers who carry out intubation works on patients, including dental works and bronchoscopies, may have a higher risk of virus infection.

\section{Single-bed ward air flow field}

The difference in exhalation activities may affect the air flow field and the dispersion of particles in an indoor environment. Compared to the air flow field without the influence of forced convection, the velocity of the exhalation flow decreases significantly under a different flow rate of chilled (cooling) air from the air conditioner. A typical air flow field for different exhalation velocities with varying flow rates of the air conditioner is shown in a velocity plot (Fig. 6).

At low exhalation velocity, the cooling air flow tends to affect the exhalation flow from the patient and deflect it to the head of the patient as shown in the velocity vector plot. The degree of deflection depends on the cooling air flow rate, where the deflection is higher under a strong cooling air flow rate. As shown in Fig. 6, the velocity distribution of the flow field around the patient is less disturbed by the low air conditioner flow rate. Conversely, when the patient is experiencing strong exhalation (such as coughing) where the exhalation velocity is as high as $15.3 \mathrm{~ms}^{-1}$, it was found that the exhalation flow is not likely to be affected by the strong cooling air flow. From the contour plot, strong exhalation flow could reach the ceiling. Due to the geometry of the room, recirculation flow at the corner of the room is possible. Since the velocity vector plot of the cooling air flow is in the downward

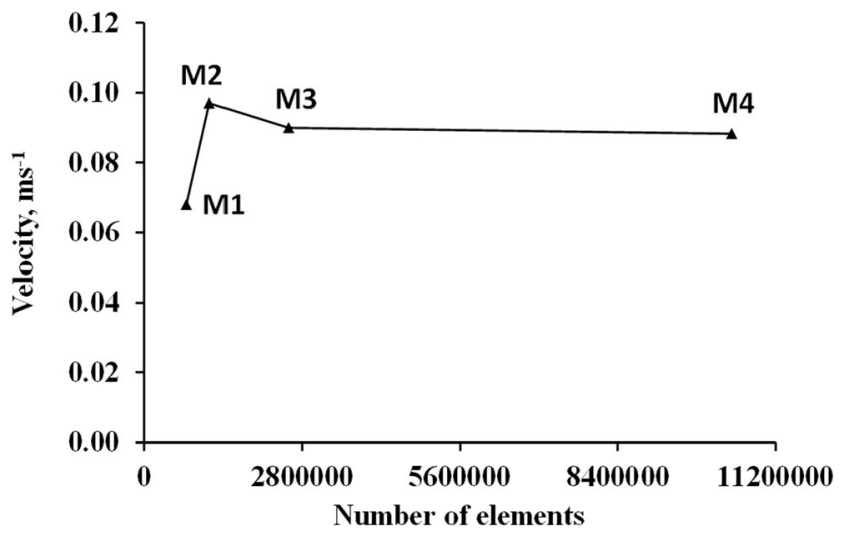

Fig. 4 Results of the mesh independent test

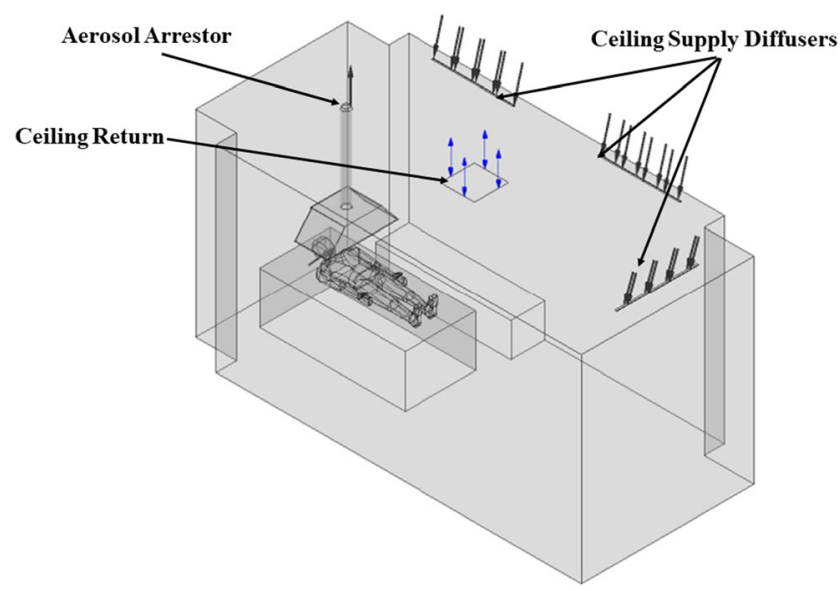

Fig. 5 Proposed new air conditioner design with ceiling supply diffusers, room return, and aerosol arrestor for the patient room

position, this further promotes the dispersion of virus-laden aerosols to the surrounding people.

\section{Transport of exhaled particle}

The simulation shows that particles exhaled from the patient's mouth remained in agglomerate form, regardless of size. The agglomerated particles begin to break up when in contact with the chilled air from the air conditioner. The turbulent flow of the chilled air may bring the virus-laden aerosols to the vicinity of the surface for succeeding deposition. When the particles arrive at the boundary layer, the virus-laden aerosols migrate to the boundary thin layer and diffuse to the surface through Brownian motion, turbulent diffusion, thermophoresis, electrostatic attraction, inertial drift, and gravitational settling (Marshall and Wilcox 2015). However, the simulation work showed that smaller particles remain suspended in the air for a long time before falling on the floor. In relation to the observation, a study done on the influenza virus with almost similar virus particles size has shown that more infectious virus particles were detected in particle sizes of below $5 \mu \mathrm{m}$ as compared to coarse particles (Milton et al. 2013).

The trajectory of the exhaled particles from a patient's mouth for weak, medium, and strong expiration is shown in Fig. 7. The simulated results predicted that large-eddy currents might account for the dispersion of particles from the patient's mouth to other places. It is also reported that turbulent air flow is one of the critical factors that promote surface deposition of the particles (Marshall and Wilcox 2015). On the other hand, Brownian diffusion is another dominant process that governs the transport of the particle after the dissipation of advective transport. Both factors support the movement of the agglomerated virus-laden aerosols in fomites at the human nose level. Hence, the results implied that it is crucial to wear a face mask and face shield to reduce the risk of inhaling the virus-laden 
Table 3 Particles mean diameter, relaxation time, terminal velocity, and time taken to fall from $1 \mathrm{~m}$ to ground level

\begin{tabular}{|c|c|c|c|c|}
\hline Group & Mean diameter, $\mu \mathrm{m}$ & Relaxation time, $\mu \mathrm{s}$ & Terminal velocity, $\mathrm{ms}^{-1}$ & Time taken to fall from $1 \mathrm{~m}$ \\
\hline 1 & 0.07 & 0.0069 & $6.87 \times 10^{-8}$ & $4137.4 \mathrm{~h}$ \\
\hline 2 & 0.1 & 0.058 & $5.72 \times 10^{-7}$ & $486.1 \mathrm{~h}$ \\
\hline 3 & 0.3 & 0.088 & $8.80 \times 10^{-7}$ & $322.3 \mathrm{~h}$ \\
\hline 4 & 0.5 & 1.02 & $1.01 \times 10^{-5}$ & $27.7 \mathrm{~h}$ \\
\hline 5 & 0.8 & 2.40 & $2.35 \times 10^{-5}$ & $11.8 \mathrm{~h}$ \\
\hline 6 & 1.0 & 3.59 & $3.53 \times 10^{-5}$ & $7.9 \mathrm{~h}$ \\
\hline 7 & 2.0 & 13.36 & $1.30 \times 10^{-4}$ & $2.1 \mathrm{~h}$ \\
\hline 8 & 5.0 & 79.63 & $7.82 \times 10^{-4}$ & $21.4 \mathrm{~min}$ \\
\hline 9 & 8.0 & 199.56 & $1.96 \times 10^{-3}$ & $8.5 \mathrm{~min}$ \\
\hline 10 & 10.0 & 313.58 & $3.08 \times 10^{-3}$ & $5.4 \mathrm{~min}$ \\
\hline
\end{tabular}

aerosols in an enclosed environment. As shown in Fig. 7 a, d, and $\mathrm{g}$ for weak exhalation cases, strong cooling airflows are predicted to deflect the exhaled particles to the side of the patient. The particles then move downward instead of upward from the patient's mouth before moving upward toward the air conditioner inlet. These particles are likely to entrain back into the cooling air supply stream and spread into the entire ward. Nevertheless, for strong exhalation cases as shown in Fig. $7 \mathrm{c}$, $\mathrm{f}$, and $\mathrm{i}$, the exhaled flow is less affected by the intensity of cooling air flow. Similar to weak and medium exhalation cases, the exhaled flow is predicted to move upward toward the air conditioner diffuser and then downward after hitting the cooling air stream. The exhaled flow then entrain back with the cooling air stream which eventually disperses throughout the room. For medium exhalation cases as shown in Fig. $7 \mathrm{~b}$, e, and h, the exhaled flow path demonstrates similar pattern as to the weak and strong exhalation. To summarize, our model shows that the exhaled particles appear to disperse in the ward under the influence of air conditioner diffusers before returning to the inlet of the air conditioner. The presence of strong air flow precludes the exhaled particles from escaping to the inlet of the air conditioner. Hence, the use of cassette air conditioning unit may not be ideal for SARSCoV-2 patient wards.

The particle deposition velocity primarily depends on the size of particles, surface characteristics, near-surface air turbulence, the electric field near the surface, and air to surface temperature. Fine particles (less than $1 \mu \mathrm{m}$ ) are heavily affected by the chilled air flows and disperse throughout the ward. This particle remains airborne for a prolonged duration before

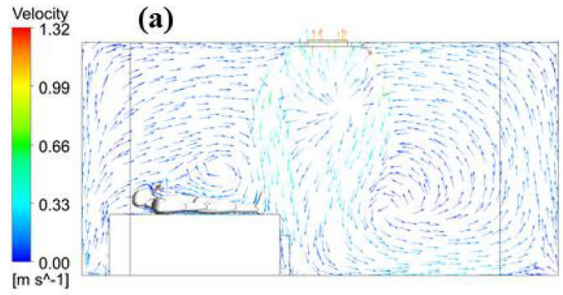

(b)

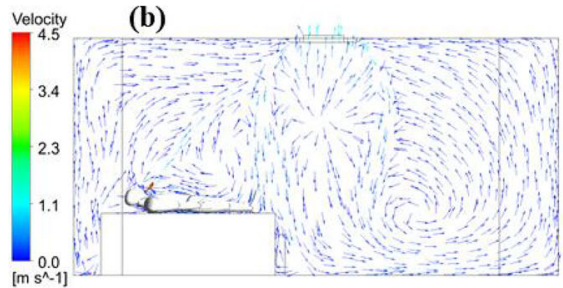

(c)

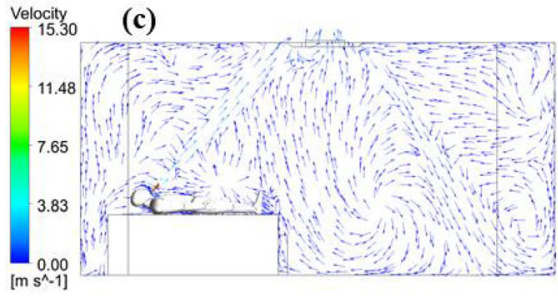

(d)

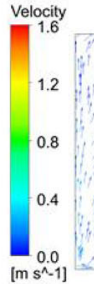

Velocit
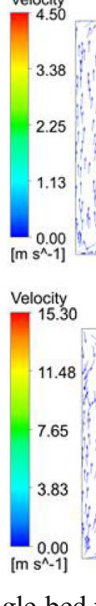

(e)

(f)
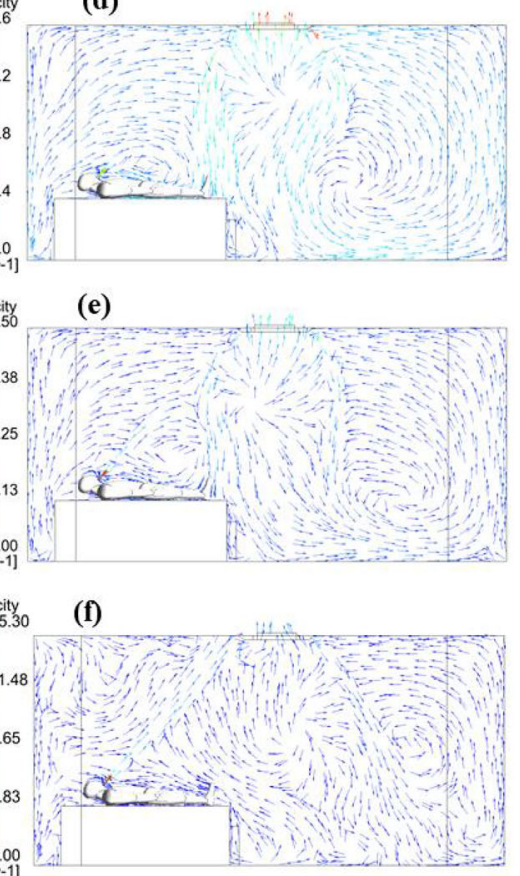

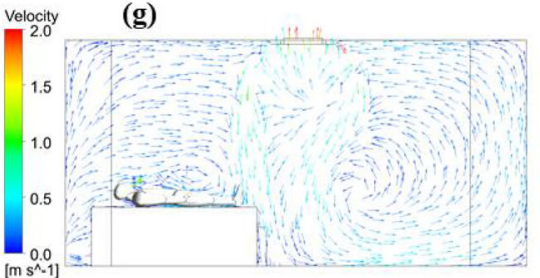

(h)
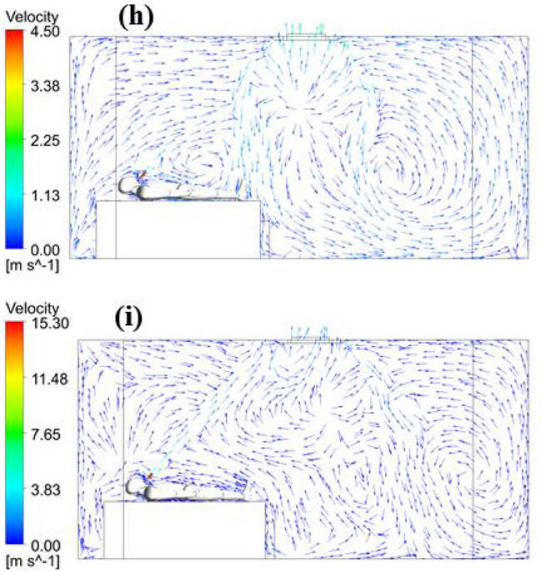

Fig. 6 Typical air flow field at the center of the single-bed ward. a Case $1, \mathbf{b}$ case $2, \mathbf{c}$ case $3, \mathbf{d}$ case 4 , e case $5, \mathbf{f}$ case $6, \mathbf{g}$ case $7, \mathbf{h}$ case $8, \mathbf{i}$ case 9 

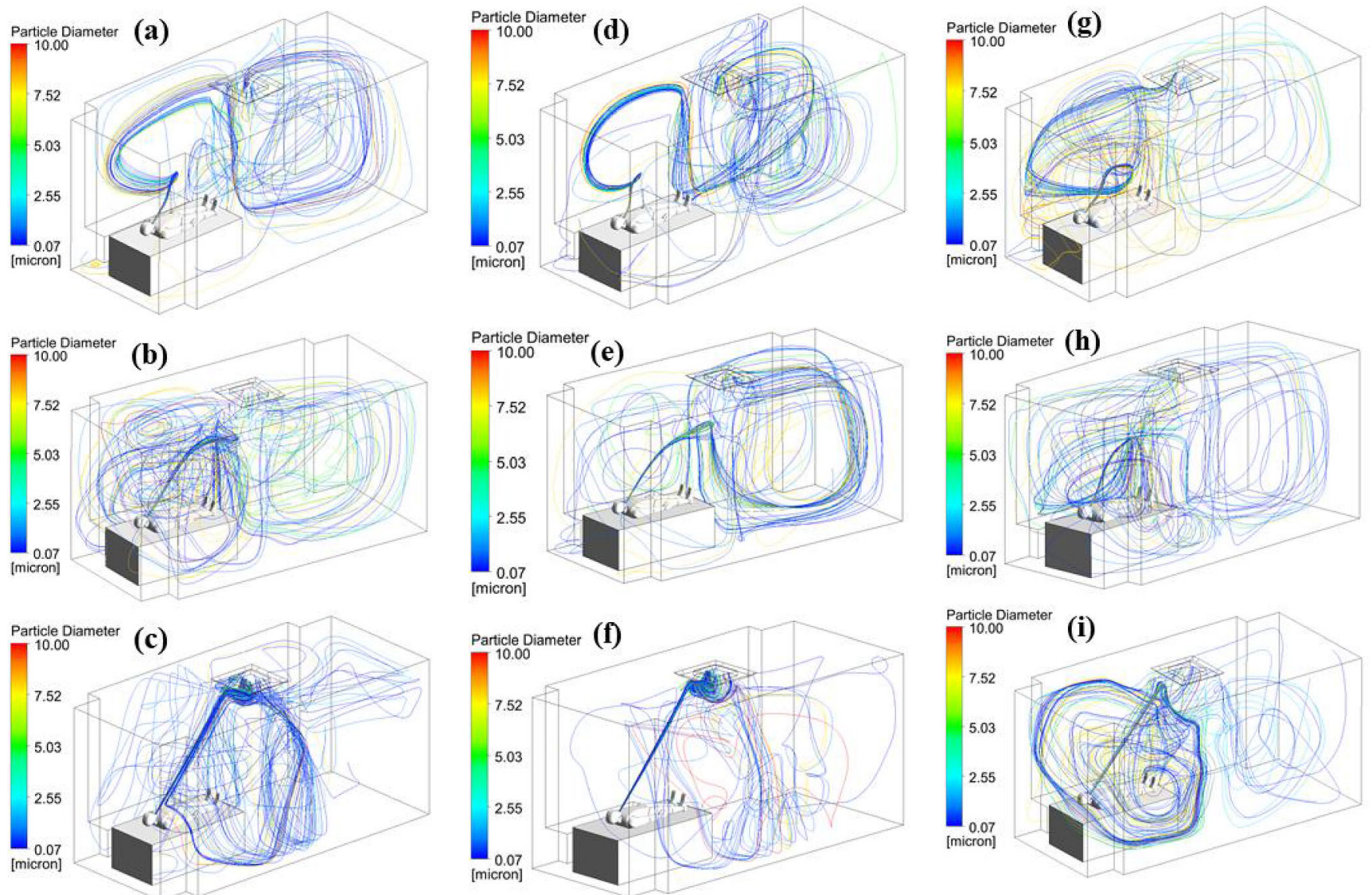

Fig. 7 Flow pathline indicating probable trajectory of the exhaled particle from the patient's mouth: a case 1, $\mathbf{b}$ case 2 , c case 3 , $\mathbf{d}$ case 4 , e case 5 , f case $6, \mathbf{g}$ case $7, \mathbf{h}$ case 8 , and $\mathbf{i}$ case 9

dropping to the floor. Gravitational settling is the main factor that drives the deposition of the particle on the floor. Furthermore, the deposition of particles on the ceiling and vertical wall is attributed to turbulent and Brownian diffusions. A majority of the particles are predicted to drop/settle on the table at the left-hand side and collected by the lowvolume air sampler. Only a tiny amount of the particles is expected to be directed/drawn toward the air conditioner inlet. On average, the simulation results show that at least $0.1 \%$ of the particle flows through the exhaust of the air conditioner inlet. The simulation study is consistent with the experimental findings from Ong et al. (2020) where the swabs taken from the air exhaust outlets in a symptomatic patient's room showed positive results.

Given a strong cooling air flow scenario, more particles are predicted to be concentrated around the head region of the patient with weak expiration (e.g., breathing) compared to strong expiration (e.g., coughing) where the particles may travel to a greater distance. Larger particles will drop off within the vicinity of the patient, while smaller particles are expected to be transported by the chilled air flow and distributed throughout the room, which may eventually adhere randomly on the wall or floor (Stadnytskyi et al. 2020). For strong expiration, the velocity of the particle did not reduce significantly after being expelled from the mouth and was not affected by weak or medium cooling air flow. The particles are predicted to penetrate the chilled air and reach the ceiling. In this simulation study, most of the particles expelled from the mouth are less than $1 \mu \mathrm{m}$. These particles are less affected by gravity or inertia but heavily influenced by the forced convection induced by the air conditioner. Since the air conditioner installed in the ward is a ceiling cassette air conditioning unit that consists of four outlets, the dispersion of the particle is expected to be in multidirectional mode. In addition, it is also implied that the air flow rate will greatly affect the dispersion of virus-laden aerosols of infectious respiratory diseases especially SARS-CoV-2. The percentage of particles lingering in the air was evaluated at the height of 1.5 $2.0 \mathrm{~m}$ above the ground level to assess the risk of exposure to the virus-laden aerosols in the breathing zones. The results are tabulated in Table 4. It is shown about $20 \%$ of the total particles found in the room were suspended in the height of 1.5$2.0 \mathrm{~m}$. On the other hand, the distribution of the particles around the patient mouth was further affected by the exhale activities and cooling air flow rate of the air conditioner. At a low exhaled velocity of $1.3 \mathrm{~ms}^{-1}$, the distribution of the particle within the diameter of $1 \mathrm{~m}$ was positively correlated with the air conditioner flow rate. Besides, this increased trend was 
also observed for case 1, case 4, and Case 7. Approximately $50 \%$ of the particles fell within the diameter of $1 \mathrm{~m}$. However, no similar trend was found in medium and high exhaled activities. The particles found out from the patient mouth of medium and high exhaled activities interact with the cooling air flow rate and caused an uneven distribution of the particle. It is heavily influenced by particle velocity as well as the air flow rate. The overall length of the room is about $6 \mathrm{~m}$ and a small number of particles are also found on the farthest end. Under enclosed environment without any fresh air being introduced into the room or air being ventilated out from the room, the safety distance of $1 \mathrm{~m}$ is not sufficient to keep people safe from the SARS-CoV-2 infection. Therefore, fresh air inlet and outlet is necessary to reduce the risk of SARS$\mathrm{CoV}-2$ transmission in any working environment.

\section{Verification of the collected air sample}

The average concentration of $\mathrm{PM}_{2.5}(48 \mathrm{~h})$ recorded in the single-bed ward was $11.25 \pm 2.05 \mathrm{\mu gm}^{-3}$ (Md Nor et al. 2021). On the other hand, the filter membranes collected from the low air volume sampler have been processed and subjected to the RT-qPCR analysis to test the presence of the SARS$\mathrm{CoV}-2$ virus. As reported in our previous work, the RT-qPCR test results showed that SARS-CoV-2 RNA was found from the filter paper of the collected air sample with a detection copy number of $74 \pm 117.1$ copies $/ \mu \mathrm{L}$ (Md Nor et al. 2021). Furthermore, the cycle threshold (CT) of the sample was less than 40 and confirmed the presence of SARS-CoV-2 in the collected sample. The current simulation work provides support for the previous experimental work to further explain and confirm the transmission of the SARS-CoV-2 RNA even when the air sampler was placed more than $1 \mathrm{~m}$ from the patient's bed, which is the primary source of SARS-CoV-2 transmission. Under the strong influence of the ventilation, the SARS-CoV-2 is able to travel further than $1 \mathrm{~m}$. Thus, healthcare workers may be exposed to virus-laden aerosols in a healthcare facility that treats COVID-19 patients, especially in an enclosed room. In general, ventilation is a key strategy for infectious disease control. Infected patients should ideally be placed in an optimally ventilated room that constantly clears the viral aerosols to reduce the infection risk of SARS-CoV-2 on healthcare workers or people living close to them.

\section{New air conditioner configuration}

Poor ventilation systems (e.g., low rate of air changes per hour, poor maintenance) in confined indoor spaces have been associated with the increased transmission or spreading of infectious diseases such as tuberculosis, influenza, measles, smallpox, chickenpox, and SARS (Chadwick et al. 1994; Josephson and Gombert 1988; Li et al. 2007; Qian and Zheng 2018; Shiu et al. 2019). The Federation of European Heating, Ventilation, and Air Conditioning Associations (REHVA) suggested that the SARS-CoV-2 virus can be picked up by the air conditioning systems if operated under the air recirculation mode. REHVA has proposed to increase the inflow of outdoor air and deactivate air recirculation mode in all indoor environments (Kurnitski et al. 2020). Herein, the computational fluid dynamic for new air conditioner configuration with aerosol arrestor was studied as shown in Fig. 8 and Fig. 9. Figure 8 illustrates the air flow distribution vector plot, whereas Fig. 9 shows the streamline plots of the probable flow path of the exhaled particles released from the patient's mouth. The air flow that passes through the linear diffusers is predicted to form a strong recirculation flow over the patient and behind the bed due to the induction characteristic of the linear diffusers (Khankari 2017). Part of the air flows upward and entrains back into the fresh air supply stream and exits the room through return diffusers and aerosol arrestor. Therefore, the installation of the air conditioner diffuser ensures sufficient fresh air supply throughout the room and maximize the comfortability for the patient or visitors in the room.
Table 4 Distribution of the aerosol particles at a height of $1.5-2.0 \mathrm{~m}$ above the ground

\begin{tabular}{llll}
\hline Case & \multicolumn{2}{l}{ Distribution of the particle at a height of $1.5-2.0 \mathrm{~m}$ in $\%$} & \\
\cline { 2 - 4 } & Total distribution & Within distance $\leq 1 \mathrm{~m}$ & Beyond distance $\geq 1 \mathrm{~m}$ \\
\hline Case 1 & 17.09 & 43.75 & 56.25 \\
Case 2 & 17.39 & 45.01 & 54.99 \\
Case 3 & 15.18 & 63.98 & 36.02 \\
Case 4 & 13.09 & 49.11 & 50.89 \\
Case 5 & 15.35 & 35.11 & 64.89 \\
Case 6 & 16.30 & 69.31 & 30.69 \\
Case 7 & 10.85 & 53.54 & 46.46 \\
Case 8 & 13.46 & 43.68 & 56.32 \\
Case 9 & 17.59 & 49.67 & 50.33 \\
\hline
\end{tabular}


Figure 9 shows the flow path of the exhaled particles released from the patient mouth for weak, medium, and strong exhalation under the influence of aerosol arrestor. As shown in the figure, the introduction of an aerosol arrestor significantly alters the flow path of the exhaled particles from the patient mouth. It is clearly shown that the incorporation of an aerosol arrestor can provide a single-pass flow to the exhaled particle and reduce the dispersion and entrainment of the exhaled particles into the supply air flow. The exhaled particles follow the direct path into the aerosol arrestor and exit the room without any obstruction and recirculation in the patient room. As a result, incorporating an aerosol arrestor in a room could help reduce the transmission risk and deposition of the airborne pathogens on the room surfaces. The hospital or patient room hygiene can be improved further by reducing the nosocomial transmission through airborne or surface contact.

COVID-19 pandemic is an immediate health emergency; control and prevention measures are urgently needed to reduce the spread of infectious diseases effectively. The new air conditioner configuration with aerosol arrestor introduced in this study can reduce pollution by minimizing air recirculation with the treatment of external air. Besides the structural changes to hospital facilities regarding ventilation system, the environmental engineering controls in healthcare settings, such as high efficiency particulate air filtration, negative pressure rooms, ultraviolet lights, and scavenging devices can also rapidly decrease the viral load in a confined space (Christian et al. 2004). Moreover, the use of protective equipment (e.g., face mask and face shield) is strongly recommended for healthcare workers when dealing with SARS-CoV-2 patients.

\section{Conclusions}

In conclusion, the dispersion of the SARS-CoV-2 in a singlebed ward under different cooling air flow rates and expiration flow rates was simulated using a three-dimensional

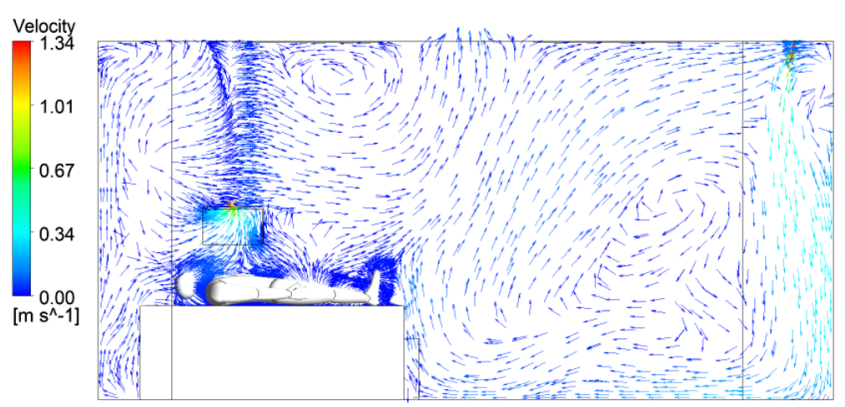

Fig. 8 Air flow pattern of the newly proposed air conditioner configuration
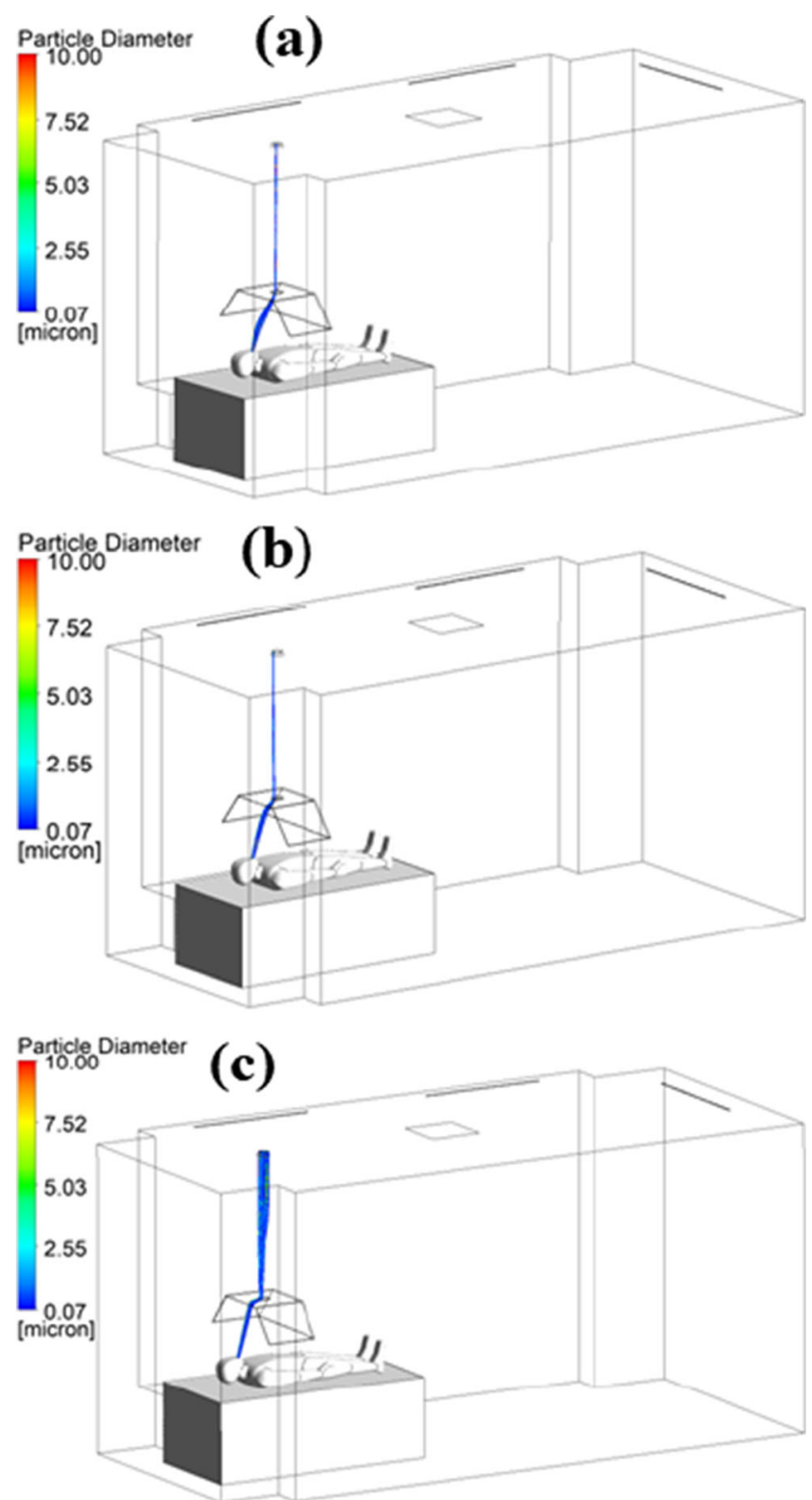

Fig. 9 The exhaled particle flow path from the patient mouth

computational fluid dynamic analysis with Lagrangian particle tracking model. The simulation work demonstrated that a strong exhalation and strong air flow instantaneously disperse the SARS-CoV-2 virus-laden aerosol throughout the room compared to weak exhalation and low air flow rate. The results suggested that the particles exhaled from patients are microscopic and the effect of gravity or inertia is negligible. The dispersion of the virus particles in the room is mainly affected by the cooling air flow and the type of air conditioner used. Introduction of linear fresh air supply diffusers, return diffuser, and aerosol arrestor can potentially provide an effective escape route for the exhaled particles to exit the patient room without recirculating in the room and deposition on the room surfaces. It should be noted that the type of air conditioners, location of the air conditioner, supply air flow rate, 
and location of the return diffusers are complex combinations that affect the air flow patterns and dispersion of the exhaled particle. These factors highly depend on the configuration of the hospital ward. Therefore, it is difficult to come up with a universal configuration of the air conditioner for all hospital ward designs. Our study suggests that the introduction of an aerosol arrestor offers an alternative solution to effectively evacuate the exhaled particles. It should be noted that the flow rate of the aerosol arrestor can be further optimized to cater for mild and severe SARS-CoV-2 patients in the ward. In addition, we concluded that aerosol transmission is a possible transmission route for the SARS-CoV-2 in an enclosed room. The findings from this study may assist in promoting the guideline on airborne isolation precautions. This may be beneficial to public health preparedness in terms of engineering control measures, including the air flow rate of the air conditioner, and the number of air exchanges in the patients' wards to better protect both patients and healthcare workers from PM containing viruses. Further, we recommend continuing the current study on the aerosol transmission of SARS-CoV-2 using a negative pressure room and include more detailed epidemiological research parameters from the SARS-CoV-2positive patients in hospital wards.

Acknowledgements We would like to thank the COVID-19 hospital in Kuala Lumpur for allowing us to perform air sampling in the single-bed ward during the Movement Control Order period. Special thanks to Mohd Hasni Jaafar to assist the project in getting permission to access the wards. We would like to thank the healthcare workers at the hospital that assist us in collecting the samples. Finally, we would like to send our appreciation to all frontline workers around the world during times of crisis.

Credit authorship contribution statement Lip Huat Saw: conceptualization; methodology; investigation; writing - original draft; data curation; formal analysis. Bey Fen Leo: conceptualization; resources; writing - review and editing, financial acquisition. Norefrina Shafinaz Md Nor: methodology; writing - review and editing; validation. Chee Wai Yip: methodology, writing - review and editing, validation. Nazlina Ibrahim: methodology; writing — review and editing; validation. Haris Hafizal Abd Hamid: sample collection, validation. Mohd Talib Latif: methodology; writing - review and editing; validation. Chin Yik Lin: conceptualization, resources, writing - review and editing. Mohd Shahrul Mohd Nadzir: conceptualization; methodology; resources; writing - review and editing; project administration; financial acquisition.

Funding The study is supported by the Universiti Kebangsaan Malaysia research grant (grant number COVID-2020-004) and the Universiti Malaya COVID-19 Special Research Grant (grant number CSRG0092020ST).

Data availability The datasets used and/or analyzed during the current study are available from the corresponding author on reasonable request.

\section{Declarations}

Ethics approval and consent to participate The air samplers of the SARS-CoV-2 were collected from 31 March 2020 to 4 April 2020 during the Movement Control Order period (from March 31, 2020, to April 4, 2020) at a hospital located in Kuala Lumpur, Malaysia. The collection of the air samples from the patients infected with SARS-CoV-2 was approved by the Research Ethics Committee, Universiti Kebangsaan Malaysia (UKM) with a reference number of UKM PPI/111/8/JEP2020-251. These samples were used to confirm the presence of the SARS-COV-2 virus on the air sampler.

Consent for publication The consent was approved by the Research Ethics Committee, Universiti Kebangsaan Malaysia (UKM), with a reference number of UKM PPI/111/8/JEP-2020-251.

Competing interests The authors declare no competing interests.

\section{References}

Ahmed F, Ara N, Deshpande V, Mollah AS, Bhowmik PK (2021) CFD validation with optimized mesh using benchmarking data of pebblebed high-temperature reactor. Prog Nucl Energy 134:103653

Aliabadi AA, Rogak SN, Green SI, Bartlett KH (2010) CFD simulation of human coughs and sneezes: a study in droplet dispersion, heat, and mass transfer, ASME 2010 International Mechanical Engineering Congress and Exposition: 1051-1060

Ansys C (2009) ANSYS CFX solver modeling guide. Release 15:162_168

Beggs CB (2020) Is there an airborne component to the transmission of COVID-19? : a quantitative analysis study. medRxiv. doi:https:// doi.org/10.1101/2020.05.22.20109991

Bourouiba L (2020) Turbulent gas clouds and respiratory pathogen emissions: potential implications for reducing transmission of COVID19. Jama 323:1837-1838. https://doi.org/10.1001/jama.2020.4756

Burke RM, Midgley CM, Dratch A, Fenstersheib M, Haupt T, Holshue M, Ghinai I, Jarashow MC, Lo J, McPherson TD, Rudman S, Scott S, Hall AJ, Fry AM, Rolfes MA (2020) Active monitoring of persons exposed to patients with confirmed COVID-19 - United States, January-February 2020. MMWR Morb Mortal Wkly Rep 69:245246

Chadwick PR, Walker M, Rees AE (1994) Airborne transmission of a small round structured virus. Lancet (London, England) 343:171. https://doi.org/10.1016/s0140-6736(94)90959-8

Chan JF, Yuan S, Kok KH, To KK, Chu H, Yang J et al (2020) A familial cluster of pneumonia associated with the 2019 novel coronavirus indicating person-to-person transmission: a study of a family cluster. Lancet (London, England) 395:514-523. https://doi.org/10.1016/ s0140-6736(20)30154-9

Christian MD, Loutfy M, McDonald LC, Martinez KF, Ofner M, Wong T, Wallington T, Gold WL, Mederski B, Green K, Low DE, Team SI (2004) Possible SARS coronavirus transmission during cardiopulmonary resuscitation. Emerg Infect Dis 10:287-293. https://doi. org/10.3201/eid1002.030700

Dietz L, Horve PF, Coil DA, Fretz M, Eisen JA, Van Den Wymelenberg K (2020) 2019 Novel Coronavirus (COVID-19) Pandemic: built environment considerations to reduce transmission. mSystems 5: e00245-e00220. https://doi.org/10.1128/mSystems.00245-20

Dong E, Du H, Gardner L (2020) An interactive web-based dashboard to track COVID-19 in real time. Lancet Infect Dis 20:533-534. https:// doi.org/10.1016/S1473-3099(20)30120-1

Edwards DA, Man JC, Brand P, Katstra JP, Sommerer K, Stone HA, Nardell E, Scheuch G (2004) Inhaling to mitigate exhaled bioaerosols. Proc Natl Acad Sci U S A 101:17383-17388. https:// doi.org/10.1073/pnas.0408159101

Fabian P, Brain J, Houseman EA, Gern J, Milton DK (2011) Origin of exhaled breath particles from healthy and human rhinovirus-infected 
subjects. J Aerosol Med Pulm Drug Deliv 24:137-147. https://doi. org/10.1089/jamp.2010.0815

Flagan RCS, John H (1988) Fundamentals of air pollution engineering. Prentice Hall 542

Guo Z-D, Wang Z-Y, Zhang S-F, Li X, Li L, Li C, Cui Y, Fu R-B, Dong Y-Z, Chi X-Y, Zhang M-Y, Liu K, Cao C, Liu B, Zhang K, Gao YW, Lu B, Chen W (2020) Aerosol and surface distribution of severe acute respiratory syndrome coronavirus 2 in hospital wards, Wuhan, China, 2020. Emerg Infect Dis 26(7):1583-1591. https://doi.org/10. 3201/eid2607.200885

Jayaweera M, Perera H, Gunawardana B, Manatunge J (2020) Transmission of COVID-19 virus by droplets and aerosols: a critical review on the unresolved dichotomy. Environ Res 188:109819 109819. https://doi.org/10.1016/j.envres.2020.10981

Jones NR, Qureshi ZU, Temple RJ, Larwood JPJ, Greenhalgh T, Bourouiba L (2020) Two metres or one: what is the evidence for physical distancing in covid-19? BMJ 370:m3223. https://oi.org/ 10.1136/bmj.m3223

Josephson A, Gombert ME (1988) Airborne transmission of nosocomial varicella from localized zoster. J Infect Dis 158:238-241. https://doi. org/10.1093/infdis/158.1.238

Khankari K (2017) Airflow dynamics of a patient room. REHVA J 5:5258

Khatoon S, Kim M-H (2020) Thermal comfort in the passenger compartment using a 3-D numerical analysis and comparison with Fanger's comfort models. Energies 13:690

Kim J-M, Chung Y-S, Jo HJ, Lee N-J, Kim MS, Woo SH, Park S, Kim JW, Kim HM, Han M-G (2020) Identification of coronavirus isolated from a patient in Korea with COVID-19. Osong Public Health Res Perspect 11:3-7. https://doi.org/10.24171/j.phrp.2020.11.1.02

Kurnitski J, Boerstra A, Franchimon F, Mazzarella L, Hogeling J, Hovorka F, et al. (2020) REHVA COVID-19 guidance document, March 17, 2020 (updates will follow as necessary) How to operate and use building services in order to prevent the spread of the coronavirus disease (COVID-19) virus (SARS-CoV-2) in workplaces. 2020(i):1-6

Kwon S-B, Park J, Jang J, Cho Y, Park D-S, Kim C, Bae G-N, Jang A (2012) Study on the initial velocity distribution of exhaled air from coughing and speaking. Chemosphere 87:1260-1264. https://doi. org/10.1016/j.chemosphere.2012.01.032

Launder BE (1972) In: Launder BE, Spalding DB (eds) Lectures in mathematical models of turbulence. Academic Press, London, New York

Li Y, Leung GM, Tang JW, Yang X, Chao CY, Lin JZ, Lu JW, Nielsen PV, Niu J, Qian H, Sleigh AC, Su HJ, Sundell J, Wong TW, Yuen PL (2007) Role of ventilation in airborne transmission of infectious agents in the built environment - a multidisciplinary systematic review. Indoor Air 17:2-18. https://doi.org/10.1111/j.1600-0668. 2006.00445.X

Li Y-Y, Wang J-X, Chen X (2020) Can a toilet promote virus transmission? From a fluid dynamics perspective. Phys Fluids 32(1994): 065107-065107

Licina D, Melikov A, Pantelic J, Sekhar C, Tham KW (2015) Human convection flow in spaces with and without ventilation: personal exposure to floor-released particles and cough-released droplets. Indoor Air 25:672-682. https://doi.org/10.1111/ina.12177

Liu J, Liao X, Qian S, Yuan J, Wang F, Liu Y, Wang Z, Wang F-S, Liu L, Zhang Z (2020a) Community transmission of severe acute respiratory syndrome coronavirus 2, Shenzhen. China Emerg Infect Dis 26(6):1320-1323. https://doi.org/10.3201/eid2606.200239

Liu Y, Ning Z, Chen Y, Guo M, Liu Y, Gali NK, Sun L, Duan Y, Cai J, Westerdahl D, Liu X, Xu K, K-f H, Kan H, Fu Q, Lan K (2020b) Aerodynamic analysis of SARS-CoV-2 in two Wuhan hospitals. Nature 582:557-560. https://doi.org/10.1038/s41586-020-2271-3

Lu J, Gu J, Li K, Xu C, Su W, Lai Z, Zhou D, Yu C, Xu B, Yang Z (2020) COVID-19 outbreak associated with air conditioning in restaurant,
Guangzhou, China, 2020. Emerg Infect Dis 26:1628-1631. https:// doi.org/10.3201/eid2607.200764

Marshall JP, Wilcox H (2015) Chapter 1 - how green and does it clean: methodologies for assessing cleaning products for safety and performance. In: Kohli R, Mittal KL (eds) Developments in Surface Contamination and Cleaning. William Andrew Publishing, Oxford, pp 1-69

McPherson MJ (1993) The aerodynamics, sources and control of airborne dust. In: McPherson MJ (ed) Subsurface Ventilation and Environmental Engineering. Springer Netherlands, Dordrecht, pp 765-811

Md Nor NS, Wai YC, Ibrahim N, Rashid ZZ, Mustafa N, Hamid HHA et al (2021) Particulate matter (PM2.5) as a potential SARS-CoV-2 carrier. Sci Rep 11:2508. https://doi.org/10.1038/s41598-02181935-9

Milton DK, Fabian MP, Cowling BJ, Grantham ML, McDevitt JJ (2013) Influenza virus aerosols in human exhaled breath: particle size, culturability, and effect of surgical masks. PLoS Pathog 9: e1003205. https://doi.org/10.1371/journal.ppat.1003205

Ong SWX, Tan YK, Chia PY, Lee TH, Ng OT, Wong MSY, Marimuthu K (2020) Air, Surface Environmental, and Personal Protective Equipment Contamination by Severe Acute Respiratory Syndrome Coronavirus 2 (SARS-CoV-2) From a Symptomatic Patient. JAMA 323:1610-1612. https://doi.org/10.1001/jama.2020.3227

Pandis JHSSN (2000) Atmospheric Chemistry and Physics, from Air Pollution to Climate Change. J Atmos Chem 37(2):212-214. https://doi.org/10.1023/A:1006483708571

Pantelic J, Tham KW (2013) Adequacy of air change rate as the sole indicator of an air distribution system's effectiveness to mitigate airborne infectious disease transmission caused by a cough release in the room with overhead mixing ventilation: a case study. HVAC\&R Research 19:947-961. https://doi.org/10.1080/ 10789669.2013.842447.10.21037/jtd.2018.01.24

Qian H, Zheng X (2018) Ventilation control for airborne transmission of human exhaled bio-aerosols in buildings. J Thorac Dis 10:S2295S2304. https://doi.org/10.21037/jtd.2018.01.24

Redrow J, Mao S, Celik I, Posada JA, Z-g F (2011) Modeling the evaporation and dispersion of airborne sputum droplets expelled from a human cough. Build Environ 46:2042-2051. https://doi.org/10. 1016/j.buildenv.2011.04.011

Santana HS, da Silva AGP, Lopes MGM, Rodrigues AC, Taranto OP, Lameu Silva J (2020) Computational methodology for the development of microdevices and microreactors with ANSYS CFX. MethodsX 7:100765. https://doi.org/10.1016/j.mex.2019.12.006

Saw LH, Poon HM, Thiam HS, Cai Z, Chong WT, Pambudi NA, King YJ (2018) Novel thermal management system using mist cooling for lithium-ion battery packs. Appl Energy 223:146-158. https://doi. org/10.1016/j.apenergy.2018.04.042

Science Media Centre (2020) Expert reaction to questions about COVID19 and viral load. https://www.sciencemediacentre.org/expertreaction-to-questions-about-covid-19-and-viral-load/. Accessed 10 May 2021

Shereen MA, Khan S, Kazmi A, Bashir N, Siddique R (2020) COVID-19 infection: origin, transmission, and characteristics of human coronaviruses. J Adv Res 24:91-98. https://doi.org/10.1016/j.jare. 2020.03.005

Shiu EYC, Leung NHL, Cowling BJ (2019) Controversy around airborne versus droplet transmission of respiratory viruses: implication for infection prevention. Curr Opin Infect Dis 32:372-379. https://doi. org/10.1097/QCO.0000000000000563

Stadnytskyi V, Bax CE, Bax A, Anfinrud P (2020) The airborne lifetime of small speech droplets and their potential importance in SARSCoV-2 transmission. PNAS 117(22):11875-11877. https://doi.org/ 10.1073/pnas.2006874117

Tang JW, Nicolle AD, Klettner CA, Pantelic J, Wang L, Suhaimi AB, Tan AYL, Ong GWX, Su R, Sekhar C, Cheong DDW, Tham KW 
(2013) Airflow dynamics of human jets: sneezing and breathing potential sources of infectious aerosols. PLoS One 8:e59970 e59970. https://doi.org/10.1371/journal.pone.0059970

Tang L-H, Tang S, Chen X-L, Zhang S, Xiong Y, Chen R, Li W, Liu HM, Xia Z-Y, Meng Q-T (2020) Avoiding health worker infection and containing the coronavirus disease 2019 pandemic: perspectives from the frontline in Wuhan. Int J Surg 79:120-124. https://doi.org/ 10.1016/j.jisu.2020.05.060

Versteeg H, Malalasekera W (1995) Computational fluid dynamics. The finite volume method

Wang J, Du G (2020) COVID-19 may transmit through aerosol. Ir J Med Sci 189(4):1143-1144. https://doi.org/10.1007/s11845-020-022182

WHO (2007) Infection prevention and control of epidemic-and pandemic-prone acute respiratory diseases in health care: WHO interim guidelines. World Health Organization, Geneva
Xie X, Li Y, Sun H, Liu L (2009) Exhaled droplets due to talking and coughing. J R Soc Interface 6(Suppl 6):S703-S714. https://doi.org/ 10.1098/rsif.2009.0388.focus

Yang S, Lee GW, Chen C-M, Wu C-C, Yu K-P (2007) The size and concentration of droplets generated by coughing in human subjects. J Aerosol Med 20(4):484-494

Yang L, Xiangdong L, Yihuan Y, Jiyuan T (2017) Effects of cough-jet on airflow and contaminant transport in an airliner cabin section. $\mathrm{J}$ Comput Multiph Flows 10(2):72-82. https://doi.org/10.1177/ $1757482 X 17746920$

Zhu S, Kato S, Yang J-H (2006) Study on transport characteristics of saliva droplets produced by coughing in a calm indoor environment. Build Environ 41(12):1691-1702. https://doi.org/10.1016/j. buildenv.2005.06.024

Publisher's note Springer Nature remains neutral with regard to jurisdictional claims in published maps and institutional affiliations. 